\title{
Research on Urbanization Resettlement Risk of Poverty Alleviation Lin $\mathrm{CHEN}^{1,2, *}$, Yu-wei LI ${ }^{2}$ \\ ${ }^{1}$ Center for Reservoir Immigration, China Three Gorges University, Yichang, Hubei, China \\ ${ }^{2}$ School of Civil Engineering and Architecture \\ China Three Gorges University, Yichang, Hubei, China
}

${ }^{*}$ Corresponding author

Keywords: Poverty Alleviation; Relocation of Urbanization; Risks.

\begin{abstract}
The current ills in the urbanization and resettlement of poverty alleviation immigrants have caused a large number of uncertainties for immigrants and society, and the poverty alleviation effect is not guaranteed. According to the characteristics of urbanization resettlement and the pain points of poverty-stricken households, and based on the understanding of the true meaning of poverty alleviation, this paper analyzes the essence of urbanization and resets the urbanization of people and summarizes the characteristics and types of the urbanization of poverty alleviation. This paper proposes that the four major risk factors for urbanized immigrants are the risk of capital reserve, social stability, physical and mental health and housing insurances. Finally, suggestions for improvement are put forward.
\end{abstract}

\section{Introduction}

Poverty is a worldwide issue. The Chinese government has long been committed to solving the trouble of poverty. Since the 1980 s, poverty alleviation has attracted attention. Now, the Chinese government further proposed to achieve poverty alleviation of rural poverty by 2020 , all the poverty-stricken counties to remove caps and solve the goal of regional overall poverty, and plans to implement the ex situ poverty alleviation and relocation of 9.81 million individuals [1]. In this policy condition, resettlement has become the first choice for poverty alleviation.

The implementation of the new poverty alleviation measures will change the living conditions of the rural needy in China. However, due to the urgent need for poverty alleviation, the causes of poverty, and the large number of poor people, the urbanization resettlement work faces a series of challenges. In some areas, there are insufficient publicity and single reporting standards. There are large differences in resettlement subsidies and unclear policies on naturalization. In short, the current chaos in urbanization has led to the immigrant poverty-stricken households taking on greater risks, bringing instability to the society and bringing new challenges to the resources and environment. Therefore, the risks in the urbanization resettlement of poverty alleviation and these risks affect the poverty alleviation result deserves further study.

\section{Definition and Types of Urbanization Resettlement for Poverty Alleviation}

Focusing on the definition of urbanization resettlement for poverty alleviation, the academic community has interpreted the two types of employment from the perspective of employment type and location of resettlement sites. WANG Bin believed that the urbanization and resettlement of poverty alleviation immigrants was a non-agricultural resettlement method that transferred the rural poor to urban areas to live and work, and mainly relied on the employment of the secondary and tertiary industries [2]. HE Lin believed that the focus of urbanization resettlement was different from other resettlement methods, which was to transform farmers into citizens and improve their own ability to become rich [3]. DU Yun-su and other believed that the current urbanization resettlement model could be divided into two ways: local urbanization and urban resettlement [4]. The implementation of each county is divided into two methods: centralized resettlement and 
decentralized resettlement. Centralized resettlement is the main form of urbanization and resettlement. The resettlement site is led by the government and will be determined through consultation with relevant departments and townships. LI Jin-fang made another interpretation of the urbanization resettlement of poverty alleviation immigrants by studying the poverty alleviation resettlement sites in the six counties of Shanxi. First, she interpreted urbanization as a process of promoting population concentration and resource intensive use. This divides the urbanization of poverty alleviation immigrants into two ways: "one step in place" and "step by step" [5]. According to the location of the resettlement site, it is divided into four modes: county center resettlement, suburban resettlement, township center resettlement and village resettlement [5]. In addition to the resettlement in the village, the other three modes belong to the category of urbanization. This paper is based on this classification method.

\section{Characteristics and Risks of Urbanization Resettlement for Poverty Alleviation}

As a systematic project, the urbanization resettlement of poverty alleviation immigrants has its complete life cycle. It is divided into three stages according to the time series: preparation period before resettlement, construction period of resettlement point, and development period after resettlement. These three stages have different work priorities, and the resettlement risks are also throughout, and there will be differences in different stages. The preparatory period before resettlement mainly involves the identification of poor households, the construction of poverty-stricken households, and the matching of poverty alleviation methods. The resettlement site construction period mainly involves the site selection, planning and construction of resettlement sites; the post-relocation development period mainly focuses on employment guidance and industry, match, settle down, etc. In addition, during the post-relocation development period, immigrants must undergo the process of residential conversion - career conversion - property conversion - identity conversion, and finally complete the entire process of immigration. The essence of risk is the uncertainty between purpose and result. The urbanization resettlement of poverty alleviation immigrants is a complex systematic project. It has the characteristics of wide planning scope, high resettlement cost, large environmental differences before and after resettlement, complex social impact, and poverty alleviation of poor families. There are many uncertain risk factors.

Combing the existing literature, domestic scholars generally study the risk factors from the personality characteristics of urbanization. DUAN Yue-fang and ZHAO Xu believed that due to the characteristics of non-agricultural, marketization of living consumption and socialization of living environment, the compensation mechanism, resource allocation mechanism and benefit sharing mechanism should be established and improved, which were social security mechanisms to evade resettlement risks [6]. DU Yun-su and others believed that the risk of urbanization was higher than that of agricultural resettlement because of the loss of land as a support for employment and social security [4]. WANG Bin conducted an in-depth analysis of the environmental capacity problem of urbanization and resettlement for poverty alleviation. The core of environmental capacity is the problem of employability. The economic environment of resettlement plays a major role in poverty alleviation. He analyzed and predicted the urban labor gap, and evaluated whether the per capita income met the immigration planning target to calculate the environmental capacity [2]. LIU Lin' study and other quantitative analysis of the multi-dimensional poverty problem of minority farmers in the contiguous destitute area have concluded that human capital, physical capital and social capital can have a significant impact on the multi-dimensional poverty of farmers [7]. ZHENG Rui-qiang and other believed that the risk of immigrants' livelihood adaptation period was mainly concentrated in the following five points: loss of original production and living resources, lack of public property and services, damage to social network, decline in health and social marginalization [8]. ZHAO Xi-liang pointed out that the education and household registration conversion and the difference in the rate of return between urban and rural education indicated that the education of rural residents could not only bring about the increase of human capital and personal income, but also help them break through the 
urban and rural household registration restrictions and enter the public, thus forming a better urban system [9]. CHEN Bin-kai and CHEN Si-yu found that the increase in the distance between immigrants and cities in the study significantly reduced the probability of immigrants entering different levels of service industry, and pointed out that trust had a significant positive impact on immigrant employment [10]. In the study on the equalization of urban and rural medical and health services, XIE Yu pointed out that the unequal health and medical services of urban and rural residents not only affected the health of the people, but also brought about social problems such as poverty, public dissatisfaction and tension between groups. Not only will it affect economic development, but it will also jeopardize social stability [11]. HUANG Wei also pointed out in the study of the impact of medical insurance policies on the effect of precision poverty alleviation: improving the health of the labor force had obvious poverty alleviation effects for low-income families [12]. WU Peng-sen believed that the current vulnerable groups, especially the relatively poor groups, had a stronger sense of "deprivation" and became a social instability factor due to the lack of intra-institutional expression of interest and game ability [13]. DONG Zhi-qiang and other empirical studies have proved that political instability would both harm economic growth and undermine social wealth [14]. Previous studies have focused on involuntary resettlement or project resettlement, providing reference for studying the urbanization resettlement of poverty alleviation.

\section{Risk Factors for Urbanization Resettlement of Poverty Alleviation}

Capital reserve. According to the literature review, the rural poor are limited by human capital and capital reserves, and there are obvious endogenous disadvantages in the job market, thus affecting the poor to get rid of poverty. This situation is particularly significant in the rural poor immigrants to urban employment: first, due to career changes, most of the poor after the immigration can no longer engage in agricultural production, the original vocational skills are useless, the original human capital is difficult to translate into effective human resources capital, which leads to difficulties in job hunting; secondly, most people after immigration have difficulty obtaining high-quality education and training in resettlement sites, unable to update their vocational skills, and can only engage in occupations with low technical content, high labor intensity, and high mobility, thus making immigrants faced with greater income reduction and unemployment risks, it is inevitable to fall into the predicament of "low human capital - low value-added occupation - low human capital investment"; in addition, the poor have limited access to occupational information, and the post-immigration detachment from the original geographical relationship and kinship relationships, losing the original social network support will lead to more difficult job hunting [9]. What's more, in some places, in the employment assistance of immigrants, the imbalance of policy intervention, the loss of social assistance, the lack of employment guidance, the lack of vocational training, and the lack of foreign aid, the employment reliability of immigrants has become a castle in the air.

From the point of view of capital reserve, the current poverty alleviation funds are not directly distributed to the poor themselves, but are invested as project funds in the construction of resettlement sites according to per capita standards. Therefore, the immigrants do not actually receive sufficient liquidity to undertake family relocation and the cost of home reconstruction, the poor income of the poor need to use family savings or even debt to achieve immigration. Secondly, after the rural poor migrate to cities and towns, they cannot continue to engage in agricultural production, lose their original agricultural income, and face the risk of lowering income during the immigration adaptation period. In addition, the current poverty alleviation funds mainly come from the government's special poverty alleviation funds, and the poverty alleviation forces are relatively single. The per capita quota for the construction of resettlement sites is lower than 50,000 to 60,000. The industry poverty alleviation and social poverty alleviation funds are insufficient, and the sources of poverty alleviation funds are limited.

Social stability. Social stability is the prerequisite for all development and construction, and the cornerstone for the smooth development of poverty alleviation. The biggest characteristic of 
traditional peasants in China is that they will relocate and not easily leave the homeland. "The relocation of the land and the nature of the people of Li min; the attachment of flesh and blood, and the willingness of human beings", the risk of social stability is easily brought about by the relocation of immigrants. Secondly, the coordination of various departments of urbanization and resettlement is complicated, and the differences in subsidies vary greatly. The lack of effective supervision of resource allocation tends to lead to imbalance of interests, which leads to conflicts of interest and thus affects policy implementation. Moreover, in the view of the aborigines in the resettlement area, immigrants are not residents and will occupy the public resources belonging to the residents and compete for local employment opportunities. In other words, immigrants as real competitors will squeeze the living space of the aborigines, combined with the value difference and the superiority of cultural barriers and the superposition of external distance, it is easy to trigger the exclusion of the aborigines. Statistics from the National Bureau of Statistics show that in 2016, China's Gini coefficient was 0.465 , exceeding the internationally recognized warning line (0.4). Inequality in income distribution makes ordinary workers' social status low, while the poor people at the bottom of wealth distribution feel more "deprived" [14]. Finally, the principles of population migration in history shows that the shortage of housing supply, the lack of medical security and the lack of social facilities caused by immigration will cause the collective consumption crisis of immigrants, bring psychological imbalances, behavioral anomies and other consequences, and become social instability factors.

Physical and mental health. Physical and mental health is the foundation of human existence and a prerequisite for getting rid of poverty and getting rich. Theorists generally believe that low incomes and high medical expenditures will lead to long-term poverty in the family, and the poor have a wide range of living conditions, poor medical and health conditions, and widespread disease hazards [9]. Under the constraints of the urban and rural dual household registration system, urban and rural inequality such as medical resource possession, health financing, health consumption and medical security [11] has made it difficult for immigrants to enjoy medical services comparable to those of resettlement residents. In terms of mental health, because the social development of poverty-stricken areas is generally backward compared with urban areas, the relative living standards of immigrants after relocation are lower, and the relative poverty will be more intense, which will easily lead to the decline of social status and psychological gap of immigrants. From the perspective of immigration, the immigrants who come to the first place must face the differences between culture and customs, and there are psychological adaptation problems. After the immigration, the traditional "social network" of "incoming friends and guarding each other" has been damaged and a new network of geopolitical relationships has not been established [15]. The issue of cultural adaptation and social relationship reconstruction may bring the collective identity crisis of immigrants, thereby affecting the mental health of immigrants.

House insurance. Previous studies have shown that the coverage of infrastructure construction and the level of public services in resettlement will directly affect the ability of immigrants to increase their income and the potential of immigrant family development. Under the existing system in China, various public welfare including education, health and culture, are matched with housing. However, the construction standards of urban resettlement sites are relatively low, and the goal is to generally meet the minimum living conditions, and housing supply is insufficient. Secondly, the cost of urbanization resettlement is generally higher than other resettlement methods. Resettlement housing is often built in the outer suburbs of cities and towns to reduce the cost of land, which makes it impossible for immigrants to effectively share the high-quality resources of the town center. What's more, the statutory rights of new immigrants cannot be guaranteed in reality.In some areas, there are insufficient administrative transparency, insufficient information disclosure, and inadequate organization and publicity, as well as the lack of political participation and awareness of immigration. Many of the rights should be difficult to fulfill in actual operation, resulting in the current living security measures cannot be immigrants. Moreover, the policies for immigration and resettlement in 
some areas are unclear, and it is difficult to ensure that immigrants realize the conversion of citizenship from the system, and thus cannot enjoy the benefits as urban residents.

\section{Summary}

Poverty alleviation is a 'thermometer' that measures social equity and people's well-being. Due to the dual social and economic structure of urban and rural separation in China for a long time, rural households, cities, farmers and citizens in household registration, land, medical services, education and There are vast differences in labor security and other systems. The inequality of rights and opportunities has caused the backwardness of agriculture and the poverty of rural areas, resulting in institutional poverty of farmers. The urbanization resettlement of poverty alleviation immigrants cannot be a simple translation of contradictions. The result of resettlement is the cultivation of new citizens or the creation of "new urban poor". This issue is worth considering. Fundamentally preventing the resettlement risk should pay attention to the long-term effect of urbanization resettlement. It should adhere to the selection of urban layout resettlement points with strong economic factors, large employment space, high level of infrastructure and public services, and large population carrying capacity; inequality in the system and the land system, to achieve social fairness and justice, to block the intergenerational transmission of poverty; to intensify the intensive new urbanization road, to achieve the social, ecological and economic effects of poverty alleviation. At the same time, developed urban areas should be encouraged to absorb poor farmers and their families into urban settlements in order to give full play to the urban agglomeration effect and share fruit of development. There are many reasons for the impact of poverty alleviation. Resettlement sites and resettlement sites are the space carriers for poverty alleviation. Whether or not to reduce resettlement risks in the early stage of decision-making is essential for achieving poverty alleviation. In short, the success or failure of poverty alleviation after resettlement lies in whether or not to realize the urbanization of people. It should be based on the "integration of the system", "economic integration", "social integration" and "cultural integration" as the ultimate evaluation criteria for the success of urbanization.

\section{Acknowledgement}

Fund Project: The Open Fund Project of Center for Reservoir Immigration, the Key Research Base of Humanities and Social Sciences in Hubei Universities, "Risks and Strategies for Urbanization and Resettlement of Poverty Alleviation Migrants" (2017KF07).

\section{References}

[1] The decision of the Central Committee of the Communist Party of China on winning the fight against poverty [J]. Jilin Agriculture, 2016, (02): 9-16. (in Chinese)

[2] WANG Bin. A preliminary study on the environmental capacity model of urban resettlement [J]. Water Resources and Hydropower Express, 2017, (03): 44-46+48. (in Chinese)

[3] HE Lin. Research on reservoir resettlement mechanism in Guizhou Province [D]. Tsinghua University, 2013. (in Chinese)

[4] DU Yun-su, LI Fei. Resettlement Strategy of Rural Reservoir Resettlement under the Background of Urbanization [J]. Rural Economy, 2014, (06): 109-112. (in Chinese)

[5] LI Jin-fang. Research on the problem of urbanization of poverty alleviation immigrants [D]. Shanxi Normal University, 2015. (in Chinese)

[6] DUAN Yue-fang, ZHAO Xu. Urbanization resettlement of water conservancy and hydropower projects: characteristics, problems and mechanism innovation [J]. Urban and Environmental Research, 2016, (03): 86-98. (in Chinese) 
[7] LIU Lin, LI Guang-hao. Dynamic Change and Influencing Factors of Multi-Different Poverty of Minority Farmers in Detachment Areas-Taking the Three States of Southern Xinjiang as an Example [J]. West Forum. 2017, 27 (01): 115-124. (in Chinese)

[8] ZHENG Rui-qiang, WANG Ying, ZHANG Chun-mei. Livelihood Risk, Supporting Resource Acceptance and Policy Optimization in Poverty Alleviation and Adaptation Period [J]. Journal of Huazhong Agricultural University (Social Science Edition), 2015, (04): 101-106. (in Chinese)

[9] ZHAO Xi-liang. Differences in the Rate of Return between Education, Household Registration and Urban and Rural Education [J]. Economic Research, 2017, 52 (12): 164-178. (in Chinese)

[10] CHEN Bin-kai, CHEN Si-yu. Flowing Social Capital-Does Traditional Clan Culture Influence Immigrant Employment? [J]. Economic Research, 2018, 53 (03): 35-49. (in Chinese)

[11]JIE Yu. Research on equalization of urban and rural health care services [D]. Shandong University, 2009. (in Chinese)

[12]Huang Wei. Research on the effect of medical insurance policy on precision poverty alleviation-Based on the URBMI pilot assessment of household survey data [J]. Economic Research, 2017, 52 (09): 117-132. (in Chinese)

[13] WU Peng-sen. The outstanding performance and formation mechanism of current social instability [J]. Exploration and Controversy, 2014, (06): 16-18. (in Chinese)

[14]DONG Zhi-qiang, LIN Wen-lian, WEI Xi-hai. Our Hostile Forces in Those Years: Political Stability and Economic Development_An Empirical Study of the "Deng Xiaoping's Hypothesis" [J]. China Journal of Economics, 2016, 3 (01): 149-178. (in Chinese)

[15]ZHENG Rui-qiang, SHI Guo-qing. Safeguarding the Rights and Interests of Poverty Alleviation and Government Responsibility [J]. Journal of Chongqing University (Social Science Edition), 2011, 17 (05): 42-47. (in Chinese)

[16] WANG Hong. Expanding the Path of Middle-income Laborers [J]. Theoretical Study, 2013 (05): 40-41. (in Chinese) 